Elsevier required licence: (c) $<2018>$. This manuscript version is made available under the CC-BY-NC-ND 4.0 license http://creativecommons.org/licenses/bync-nd/4.0/ 


\title{
Predictors of health-related quality of life in Korean patients with myocardial infarction: A longitudinal observational study
}

\author{
Kyoungrim Kang ${ }^{\mathrm{a},}$, Leila Gholizadeh ${ }^{\mathrm{a}}$, Sally C Inglis ${ }^{\mathrm{a}}$, Hae-Ra Han $^{\mathrm{b}}$ \\ ${ }^{a}$ University of Technology Sydney, Sydney, NSW, Australia \\ ${ }^{\mathrm{b}}$ The Johns Hopkins University, Baltimore, MD, USA \\ * The corresponding author: Kyoungrim Kang, E-mail address: Kyoungrim.Kang@student.uts.edu.au \\ Postal address: PO Box 123, Level 3, UTS Building 10, 235 Jones St, Ultimo NSW 2007, Australia
}

Acknowledgement: Not applicable.

Conflict of Interest: None.

Funding sources: All authors have no funding source to declare.

Keywords: Factors; Korea; myocardial infarction; predictors; quality of life. 


\section{Abstract}

Background: Experience of myocardial infarction (MI) negatively affects different aspects of health-related quality of life (HRQoL).

Objectives: This study aimed to examine trends in HRQoL of MI patients and to identify demographic, clinical and psychosocial predictors of HRQoL at three months.

Methods: A total of 150 patients in South Korea were completed the study questionnaires at baseline. After three months from discharge, 136 participants completed follow-up questionnaires, including the Korean version of the MacNew Quality of Life after Myocardial Infarction Questionnaire (MacNew).

Results: HRQoL significantly improved over three months. Younger age, ST-elevation MI, and higher LVEF, lower level of depression, better understanding of the illness and higher perceived social support at baseline were associated with better HRQoL at three months.

Conclusion: Providing adequate information about the illness and social support as well as reducing negative psychological experiences in early days after MI may improve HRQoL of MI patients. 


\section{Introduction}

Experience of myocardial infarction (MI) poses a threat to health-related quality of life (HRQoL). ${ }^{1}$ Within the first year after $\mathrm{MI}^{2}$, about $20 \%$ of patients experience persistent symptoms including fatigue, sleep disturbance and shortness of breath as well as reoccurrence of MI, stroke, or death ${ }^{3}$. It is common that patients after MI report lower HRQoL scores than those without MI; however, HRQoL scores improve in most patients over time. ${ }^{4}$ The results of a longitudinal study conducted by Eriksson et al. ${ }^{5}$ showed that patients' HRQoL, measured by the Short Form 36 Health Survey Questionnaire (SF-36), was lower than their partners and those without the experience of MI at a one-month follow-up. However, HRQoL of MI patients showed improvement with higher scores than their partners or those without MI over time, at seven months, 13 months, and 25 months from MI. Similarly, another study found that improvement of HRQoL in patients with MI was statistically significant from four weeks to six months, as measured with both the Medical Outcomes Short Form-12 (SF-12) and the Seattle Angina Questionnaire (SAQ). ${ }^{6}$ Multiple factors were reported to affect HRQoL of patients after MI. ${ }^{4}$ These factors included female gender, living alone and low education level and higher depression, anxiety and stress. Disease-related factors such as severity of MI and the associated symptoms were also found to be negatively associated with HRQoL post-MI. In addition, MI affects different aspects of HRQoL, including the physical, emotional and social functioning of patients. Patients' psychological experiences including depression, anxiety, stress, level of social support, perception of the disease, and self-efficacy are also associated with HRQoL. ${ }^{7}$ Assessment of HRQoL can supplement the traditional measures of health outcomes as this subjective report represents the patient-centred health status individually in broader aspects. It can also be assumed that diminished HRQoL negatively affects morbidity and mortality in cardiac patients as well as in those without heart disease. ${ }^{4}$ Studying this multi-dimensional 
concept thus could lead to a broader understanding of patients' recovery status. ${ }^{8}$

Understanding those factors that contribute to HRQoL post-MI, particularly modifiable factors, can open a window of opportunities to improve recovery experience and disease outcomes of patients post-MI. Although some studies have examined the relationships between different demographic, clinical and psychological factors and HRQoL after MI, few studies have investigated the predictors of HRQoL using robust statistics to enable development of reliable models. These studies are particularly scarce in Asian countries including South Korea.

The purposes of the current study were to examine the trends in HRQoL of patients and to identify the role of different demographic, clinical and psychosocial variables in predicting HRQoL of these patients at the three-month follow-up.

\section{Methods}

\section{Overview of the design}

This study used a longitudinal observational design to examine the trends in changes of HRQoL, from baseline to three months, in patients with MI in South Korea and to identify factors predicting HRQoL of the patients at three months post-MI. The majority of infarct healing occurs within 3-4 months of $\mathrm{MI}^{9}$ and most patients can resume their pre-illness activities including returning to work within three to six months after MI, positively affecting their emotional well-being. ${ }^{10}$ Therefore, as the patients' functioning status improves, improvement in HRQoL is also expected.

Treatment of acute myocardial infarction (AMI) in South Korea includes reperfusion strategies using pharmaceutical interventions, percutaneous coronary intervention (PCI) or coronary artery bypass graft. More than $90 \%$ of patients with acute MI undergo drug-eluting stenting and there is no gender difference in the initial treatment of AMI. However, 
prescription of medical therapy for secondary prevention has been reported to be suboptimal. ${ }^{11}$ After discharge from hospital, patients visit an outpatient clinic two or three times within the first month and then once or twice a month for the next three months.

\section{Human subjects}

Participants were recruited from the comprehensive cardiovascular centres of two tertiary hospitals in the southern part of South Korea. They were asked to complete study questionnaires at baseline (within one week after MI) and at three-month follow up.

\section{Inclusion/exclusion criteria}

Inclusion criteria required admission with a diagnosis of either ST-elevation myocardial infarction (STEMI) or non-ST elevation myocardial infarction (NSTEMI), ability to understand and speak Korean, be a Korean resident, ability to understand the study procedure and give an informed consent. Patients were excluded if they had cognitive impairment or if they were participating in other interventional studies that might have affected the results of the current study. Patients' cognitive status, capacity to provide consent, and to understand the study questionnaires were assessed prior to enrolment in accordance with the Fan et al.'s two step approach. ${ }^{12}$ A charge nurse in each study site firstly confirmed the patient's ability to participate in the study, and then each patient was asked to state their full name and answer which colour they had seen among one of three sheets of coloured paper. After the cognitive assessment, patients who signed the consent form were subsequently enrolled in the study.

\section{Rationale for the sample size}

The formula of ' $\mathrm{N}>50+8^{*}$ the number of independent variables ${ }^{13}$ was used to calculate the study sample size. Using this formula, a sample size of 138 was needed to allow for inclusion of 11 independent variables into the regression model. 


\section{Procedures}

The Institutional Review Boards of the participating hospitals (PNUH IRB no. H-1505-008029 and PNUYH IRB no. 05-2015-072) and the Human Research Ethics Committee of the involving university (UTS HREC Approval No. 2015000254) approved the ethics of the study. Potential participants were provided with information about the study verbally and in writing in Korean. Participations who were interested in the study gave consent and were enrolled in the study. The confidentiality privacy and volunteer participation were maintained throughout the study. Participants were assured that their participation was completely voluntary and that they could withdraw at any time they wished. The individual's participation was not disclosed to others and the data collection was held individually in a room where the patients' privacy could be protected. Follow-ups were scheduled according to participants' preferences to minimise inconvenience. Data collection was completed by the principle investigator whose first language is Korean (KK). Two cardiologists and several nurse managers were consulted to discuss strategies for participant recruitment, study questionnaires, and ethical considerations. Figure 1 describes the process of screening, enrolment and follow-up of the study participants. A total of two hundred and fifteen consecutive patients were screened for the study inclusion criteria from August 2015 to February 2016; of whom 17 patients were excluded due to poor hearing, five patients were discharged before enrolment, and one patient was unconscious. The remaining eligible patients were invited to participate in the study. Among those who were invited to the study, 23 patients declined to participate because of perceived poor health condition, including dyspnoea, pain and tremor and 19 patients declined the invitation without giving a specific reason.

A total of 150 patients $(69.8 \%)$, who provided informed consent were enrolled in the study and completed the study questionnaires at baseline (within one week after MI) and at the 
three-month follow-up. The participants were asked to complete the questionnaires by themselves or the researcher read out the questions to the participant, obtained, and recorded their responses. Of the 150 participants at baseline, ten were lost to follow-up and four passed away. As a result, 136 participants completed the three-month follow-up questionnaires. The three-month follow-up questionnaires were completed in a face-to-face session at an outpatient department during a routine follow-up check-up. Some participants who did not have enough time to complete the three-month follow-up questionnaires at the outpatient department or the researcher failed to meet them at their follow-up appointment completed the follow up questionnaires over the telephone.

Figure 1. Flow diagram of participants with MI from screening, recruitment, withdrawal to completion.

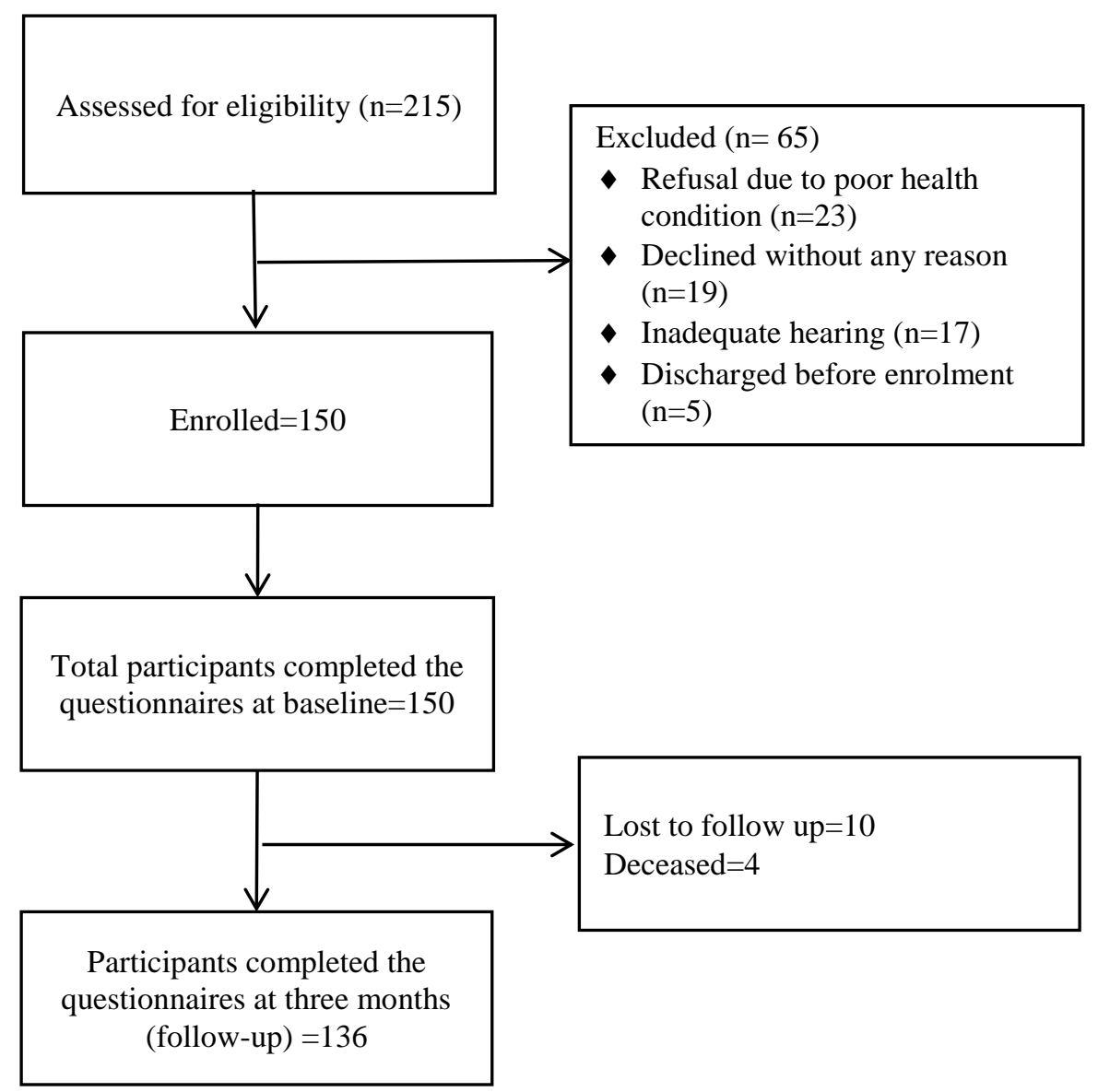




\section{Variables and measures}

Variables and conceptual framework

A thorough review of previous literature ${ }^{7}$ and the revised Wilson \& Cleary model for HRQoL ${ }^{14}$ guided the selection of independent variables for the study. The participants' baseline psychosocial status (depression, anxiety, stress, illness perception, and social support), demographic factors (age, gender, education level and subjective financial status), and clinical factors (type of MI and LVEF) were examined for their contribution to HRQoL of the participants at the three-month follow-up.

Demographic and clinical profiles

Information on demographical profiles of the participants was collected, which included: age, gender, marital status, education level, employment status and self-assessed financial situation (categorised as excellent/good/only fair/poor). Information on participants' clinical profiles included: type of MI (STEMI/NSTEMI), smoking (non-smoker/previous smoker/current smoker), alcohol consumption (yes/no), LVEF, history of high blood pressure, diabetes, stroke, other heart diseases, previous MI and other comorbidities. This information was collected from the medical records of the participants after obtaining their consent.

Psychosocial profile Depression, anxiety, and stress Among psychosocial factors studied in previous literature, depression, anxiety and stress has been the most commonly examined factors negatively affecting HRQoL of patients with MI. ${ }^{15-17}$ We used the Korean version of the DASS $21^{18}$ to assess the participant's physiological status. The DASS 21 is the short form of the DASS 42, consisting of 21 items with each item scoring from 0 (never) to 3 (almost always) and the total score for the scale 
ranging from 0 to 63 , with higher scores indicating greater depression, anxiety and stress. ${ }^{19}$ The measurement can be divided into three dimensions of depression, anxiety and stress. Each dimension encompasses seven items with the total scores of the subscales ranging from 0 to $21 .{ }^{19}$

DASS 21 is a valid tool. In the original study, the internal consistencies of the subscales have been reported as 0.91 for depression, 0.84 for anxiety and 0.90 for stress (Lovibond \& Lovibond 1995). In a Korean study using the Korean version of the DASS 21, the alpha coefficients were ranged from 0.72 to 0.81 for the subscales of depression, anxiety and stress. ${ }^{20}$ In the current study, the alpha coefficient for the total scale was 0.86 , and for the subscales of depression 0.85 , anxiety 0.52 , and stress 0.80 . We included the total scores of the DASS 21 in the regression analysis.

\section{IIIness perception}

The available evidence suggested that patients with more positive illness perceptions following MI showed better quality of life. ${ }^{21}$ Thus, this study examined participants' understanding of their MI, using a single item extracted from the Brief Illness Perception Questionnaire (B-IPQ). This item was scored on a Likert type scale ranging from 0 (“don't understand at all") to 10 ("understand very clearly"). ${ }^{22}$ The Korean version of the item was prepared for the purpose of this study.

\section{Social support}

The ENRICHD Social Support Inventory (ESSI) has been developed to measure the social support of patients with coronary heart disease, in particular, patients with MI. This questionnaire consists of seven items addressing different types of social support including structural, instrumental, and emotional support. Response rate for all the items ranges from 1 (none of the time) to 5 (all the time), except for item 7, which is scored 4 for "yes" or 2 for 
"no". ${ }^{23}$ The seven items can be summed as the total score ranging from 8 (no support) to 34 (maximum level of support). ${ }^{24}$ The validation studies of the scale on the cardiac patient population have shown high internal consistencies, with alpha coefficients ranging from 0.88 to $0.94 .{ }^{24}$ A Korean version of the scale was prepared for the purpose of this study and the alpha coefficient of the study sample was 0.93 . The ESSI was firstly translated into Korean by the principal researcher whose first language is Korean, and then reviewed by two health professionals and two laypersons who were Korean native speakers.

Health-related quality of life

The MacNew Quality of Life after Myocardial Infarction Questionnaire (MacNew) is a disease specific valid tool to measure HRQoL of patients with MI. For the purpose of this study, the tool was translated into Korean language and validated on a sample of Korean patients with MI. The MacNew includes 27 items with responses ranging from 1 to 7 on a seven point Likert scale. The items of this instrument fall into three physical (13 items), emotional (14 items) and social dimensions (13 items $)^{25,26}$, although loadings of items onto each construct vary slightly across studies. The total mean score and each domain can be calculated as a mean score with a range between 1 and 7 , with higher scores representing better HRQoL. The minimal important difference (MID) on the global MacNew and the three subscales is determined by 0.50 points as a significant change. ${ }^{25}$ The reliability of the total MacNew has been well established in a plethora of previous studies, with Cronbach's alpha coefficients ranging from 0.85 to $0.94 .{ }^{27-29}$ The Cronbach's alpha coefficient of the Korean MacNew in the current study was also high at 0.90 for the total scale, and $0.86,0.85$ and 0.88 for the emotional, physical and social subscales, respectively. 


\section{Statistical analysis}

Data were analysed using SPSS version 24.0 (SPSS Inc., Chicago, IL, USA). A descriptive analysis of participants' characteristics was performed using means, standard deviations (SD), frequencies and percentages. The MacNew scores were normally distributed, thus paired-samples t-tests were used to examine changes between baseline MacNew and threemonth follow-up scores. Tolerance, variance inflation factor (VIF) and correlations between the independent variables were analysed for multicollinearity. The results were indicated the absence of multicollinearity with a tolerance value of higher than 0.10 , a VIF value of below 10 or Pearson correlation coefficients of lower than $0.90 .{ }^{13}$ Thus, 11 independent variables were included in the backward stepwise regression model. At each elimination step, one or two most insignificant factors were removed from the model until only significant predictors remained. The level of statistical significance of analyses was set at $p<0.05$ (two-tailed).

\section{Results}

\section{Participant characteristics}

The mean age of participants at baseline was $64.63(\mathrm{SD}=11.48)$ years, with a range of 21 to 86 years. Most of the participants were aged 55 years or older $(n=120,80.0 \%)$, male $(n=107$, $71.3 \%)$, married $(n=129,86.0 \%)$ and educated at a middle school level or higher $(n=110$, $73.3 \%)$. Forty per cent of the participants $(n=60)$ were employed at the time of enrolment, but only $14.0 \%(\mathrm{n}=21)$ perceived their financial situation as 'excellent' or 'good'. The mean value of $\mathrm{LVEF}$ was $50.86 \%$ ( $\mathrm{SD}=10.80$ ) with a range from $17 \%$ to $70 \%$. One third of the patients in this study $(n=50,33.3 \%)$ were current smokers and $28.7 \%$ of them $(n=43)$ answered 'yes' to the drinking question. The demographic and clinical characteristics of the participants at baseline are presented in Table 1. 
Table 1. Participants' demographic and clinical characteristics at baseline $(\mathrm{n}=150)$

\begin{tabular}{|c|c|c|c|c|}
\hline \multicolumn{3}{|l|}{ Demographic factors } & $\begin{array}{l}\mathrm{n} \\
30\end{array}$ & $\begin{array}{l}\% \\
20.0\end{array}$ \\
\hline Age (years) & $\begin{array}{l}<55 \\
55-64 \\
65-74 \\
75 \leq\end{array}$ & & $\begin{array}{l}30 \\
43 \\
43 \\
34\end{array}$ & $\begin{array}{l}20.0 \\
28.7 \\
28.7 \\
22.6\end{array}$ \\
\hline Gender & \multicolumn{2}{|l|}{$\begin{array}{l}\text { Female } \\
\text { Male }\end{array}$} & $\begin{array}{l}43 \\
107\end{array}$ & $\begin{array}{l}28.7 \\
71.3\end{array}$ \\
\hline Marital status & \multicolumn{2}{|c|}{$\begin{array}{l}\text { Married } \\
\text { Never married/Separated/Divorced/ } \\
\text { Widowed }\end{array}$} & $\begin{array}{l}129 \\
21\end{array}$ & $\begin{array}{l}86.0 \\
14.0\end{array}$ \\
\hline Level of education & \multicolumn{2}{|c|}{$\begin{array}{l}\text { Primary or less } \\
\text { Middle school } \\
\text { High school } \\
\text { Undergraduate or more }\end{array}$} & $\begin{array}{l}40 \\
25 \\
54 \\
31\end{array}$ & $\begin{array}{l}26.7 \\
16.7 \\
36.0 \\
20.6\end{array}$ \\
\hline Employment status & \multicolumn{2}{|c|}{$\begin{array}{l}\text { Employed } \\
\text { Unpaid family workers/Retired / } \\
\text { Unemployed }\end{array}$} & $\begin{array}{l}60 \\
90\end{array}$ & $\begin{array}{l}40.0 \\
60.0\end{array}$ \\
\hline Financial status (Subjective) & \multicolumn{2}{|l|}{$\begin{array}{l}\text { Excellent / Good } \\
\text { Only fair / Poor }\end{array}$} & $\begin{array}{l}21 \\
129\end{array}$ & $\begin{array}{l}14.0 \\
86.0\end{array}$ \\
\hline \multicolumn{5}{|l|}{ Clinical factors } \\
\hline Type of MI & \multicolumn{2}{|l|}{$\begin{array}{l}\text { STEMI } \\
\text { NSTEMI }\end{array}$} & $\begin{array}{l}57 \\
79\end{array}$ & $\begin{array}{l}41.9 \\
58.1\end{array}$ \\
\hline Smoking & \multicolumn{2}{|l|}{$\begin{array}{l}\text { Non-smoker } \\
\text { Previous smoker } \\
\text { Current smoker }\end{array}$} & $\begin{array}{l}85 \\
15 \\
50\end{array}$ & $\begin{array}{l}56.7 \\
10.0 \\
33.3\end{array}$ \\
\hline Alcohol consumption & \multicolumn{2}{|l|}{$\begin{array}{l}\text { Yes } \\
\text { No }\end{array}$} & $\begin{array}{l}43 \\
107\end{array}$ & $\begin{array}{l}28.7 \\
71.3\end{array}$ \\
\hline \multirow[t]{12}{*}{ Medical Characteristics } & \multirow[t]{2}{*}{ Hypertension: } & Yes & 75 & 50.0 \\
\hline & & No & 75 & 50.0 \\
\hline & \multirow[t]{2}{*}{ Diabetes: } & Yes & 47 & 31.3 \\
\hline & & No & 103 & 68.7 \\
\hline & \multirow[t]{2}{*}{ Stroke: } & Yes & 8 & 5.3 \\
\hline & & No & 142 & 94.7 \\
\hline & \multirow[t]{2}{*}{ Other heart disease: } & Yes & 25 & 16.7 \\
\hline & & No & 125 & 83.3 \\
\hline & \multirow[t]{2}{*}{ Previous MI: } & Yes & 37 & 24.7 \\
\hline & & No & 113 & 75.3 \\
\hline & \multirow[t]{2}{*}{ Other comorbidities: } & Yes & 58 & 38.7 \\
\hline & & No & 92 & 61.3 \\
\hline
\end{tabular}

$\mathrm{L} \overline{\mathrm{VEF}}$ = Left Ventricular Ejection Fraction; MI = Myocardial Infarction; NSTEMI = non-ST elevation myocardial infarction; SD = Standard Deviation; STEMI $=$ ST-elevation myocardial infarction.

\section{Changes in HRQoL}

The changes in total scores of HRQoL and the subscales from baseline to three-month follow-up are shown in Table 2. Overall, the results indicate that HRQoL of the participants 
showed statistically significant improvements in all the dimensions of the MacNew with a mean difference of 0.98 for emotional, 1.11 for physical, and 1.06 for social dimensions. The total score of the MacNew also improved significantly from baseline to three-month followup, with the mean difference of 1.03 .

Table 2. Changes in the MacNew scores of the participants over three months $(n=136)$

\begin{tabular}{|c|c|c|c|c|c|c|c|}
\hline \multirow[b]{2}{*}{ Variables (range) } & \multicolumn{2}{|l|}{ Baseline } & \multicolumn{2}{|c|}{ Follow-up } & \multirow{2}{*}{$\begin{array}{l}\text { Mean difference } \\
(95 \% \text { CI })\end{array}$} & \multirow[b]{2}{*}{$t$} & \multirow[b]{2}{*}{$p$} \\
\hline & Mean & SD & Mean & SD & & & \\
\hline MacNew total & 4.51 & 0.81 & 5.54 & 0.78 & $1.03(0.88,1.17)$ & 13.896 & 0.000 \\
\hline Emotional & 4.42 & 0.82 & 5.40 & 0.85 & $0.98(0.81,1.14)$ & 11.617 & 0.000 \\
\hline Physical & 4.43 & 0.99 & 5.55 & 0.85 & $1.11(0.95,1.27)$ & 13.834 & 0.000 \\
\hline Social & 4.83 & 0.93 & 5.89 & 0.82 & $1.06(0.89,1.23)$ & 12.356 & 0.000 \\
\hline
\end{tabular}

\section{Predictors of HRQoL at three-month follow-up}

Table 3 shows the results the backward elimination stepwise regression analysis. The first model of the stepwise regression included a total of 11 variables - age, gender, the level of education, perceived financial status, type of MI (STEMI/NSTEMI), LVEF, depression, anxiety, stress, illness perception, and social support. Of these variables, age, LVEF, depression, stress, illness perception, and social support were statistically significant. At the next step, the two least significant variables_-education level and perceived financial status - were eliminated, resulting in gender, type of MI and anxiety to become statistically insignificant predictors. Gender and anxiety, as the least significant predictors were removed from the model at the third step, resulting in type of MI becoming a statistically significant predictor, while stress showed the least correlation with HRQoL. Following the removal of stress in the next step, all the six remaining variables showed statistically significant correlations with HRQoL at three months post-MI. These predictors included age, type of MI, LVEF, depression, illness perception and social support. Younger age $(\beta=-0.216, t=-2.715$, 
$p=0.008$ ) was closely associated with better HRQoL at three months. Being diagnosed with STEMI $(\beta=-0.163, t=-2.119, p=0.036)$ or having higher LVEF at baseline $(\beta=0.207, t=2.606$, $p=0.010$ ) were significant predictors of higher HRQoL at three months. Higher score of depression at baseline $(\beta=-0.201, t=-2.644, p=0.009)$ was closely associated with lower HRQoL at three months. In addition, patients' better understanding of their illness $(\beta=0.213$, $t=2.755, p=0.007)$ or perceived higher social support at baseline $(\beta=0.199, t=2.515, p=0.013)$ were significant predictors of better HRQoL at three months. The final model of the current study explained $27.4 \%$ of the variance in HRQoL (adjust $R 2=0.241, F=8.129, p=0.000$ ). 
Table 3. Predictors of HRQoL at three-month follow-up using the backward elimination stepwise regression analysis

\begin{tabular}{|c|c|c|c|c|c|c|c|c|c|c|c|c|c|c|}
\hline \multirow{2}{*}{$\begin{array}{l}\text { Demographic } \\
\text { factors }\end{array}$} & \multicolumn{2}{|c|}{ Collinearity } & \multicolumn{3}{|l|}{ Step 1} & \multicolumn{3}{|l|}{ Step 2} & \multicolumn{3}{|l|}{ Step 3} & \multicolumn{3}{|l|}{ Step 4} \\
\hline & Tol. & VIF & $\beta$ & $t$-value & $p$ & $\beta$ & $t$-value & $p$ & $\beta$ & $t$-value & $p$ & $\beta$ & $t$-value & $p$ \\
\hline Age & 0.738 & 1.354 & -0.175 & -2.034 & $0.044 *$ & -0.180 & -2.239 & $0.027^{*}$ & -0.206 & -2.602 & $0.010^{*}$ & -0.216 & -2.715 & $0.008 * *$ \\
\hline Gender & 0.758 & 1.318 & 0.098 & 1.148 & 0.253 & 0.112 & 1.390 & 0.167 & - & - & - & - & - & - \\
\hline Education level & 0.543 & 1.840 & 0.035 & 0.352 & 0.726 & - & - & - & - & - & - & - & - & - \\
\hline Financial status & 0.726 & 1.377 & 0.095 & 1.097 & 0.275 & - & - & - & - & - & - & - & - & - \\
\hline \multicolumn{15}{|l|}{ Clinical factors } \\
\hline Type of MI & 0.887 & 1.128 & -0.124 & -1.571 & 0.119 & -0.133 & -1.706 & 0.090 & -0.166 & -2.188 & $0.031^{*}$ & -0.163 & -2.119 & $0.036^{*}$ \\
\hline LVEF & 0.827 & 1.210 & 0.195 & 2.391 & $0.018^{*}$ & 0.180 & 2.277 & $0.024 *$ & 0.204 & 2.601 & $0.010^{*}$ & 0.207 & 2.606 & $0.010 *$ \\
\hline \multicolumn{15}{|c|}{ Psychosocial factors } \\
\hline Depression & 0.603 & 1.660 & -0.252 & -2.637 & $0.009^{* *}$ & -0.238 & -2.527 & $0.013^{*}$ & -0.272 & -3.253 & $0.001 * *$ & -0.201 & -2.644 & $0.009 * *$ \\
\hline Anxiety & 0.581 & 1.722 & -0.111 & -1.142 & 0.256 & -0.101 & -1.048 & 0.297 & - & - & - & - & - & - \\
\hline Stress & 0.678 & 1.476 & 0.203 & 2.253 & $0.026^{*}$ & 0.193 & 2.165 & $0.032 *$ & 0.165 & 1.946 & 0.054 & - & - & - \\
\hline B-IPQ 7 & 0.823 & 1.215 & 0.191 & 2.345 & $0.021 *$ & 0.179 & 2.309 & $0.023^{*}$ & 0.205 & 2.674 & $0.008 * *$ & 0.213 & 2.755 & $0.007 * *$ \\
\hline \multirow[t]{2}{*}{ ESSI } & 0.723 & 1.383 & 0.244 & 2.803 & $0.006^{* *}$ & 0.224 & 2.797 & $0.006^{* *}$ & 0.227 & 2.849 & $0.005 * *$ & 0.199 & 2.515 & $0.013^{*}$ \\
\hline & & & \multicolumn{3}{|c|}{$\begin{array}{l}R^{2}=0.320, \text { adjusted } R^{2}=0.260 \\
F=5.312(p=0.000)\end{array}$} & \multicolumn{3}{|c|}{$\begin{array}{l}R^{2}=0.314, \text { adjusted } R^{2}=0.265 \\
F=6.397(p=0.000)\end{array}$} & \multicolumn{3}{|c|}{$\begin{array}{l}R^{2}=0.295, \text { adjusted } R^{2}=0.257 \\
F=7.659(p=0.000)\end{array}$} & \multicolumn{3}{|c|}{$\begin{array}{l}R^{2}=0.274, \text { adjusted } R^{2}=0.241 \\
F=8.129(p=0.000)\end{array}$} \\
\hline
\end{tabular}

$\beta=$ Standardised $\beta$; B-IPQ 7 = Brief Illness Perception Questionnaire $7^{\text {th }}$ item; ESSI = ENRICHD Social Support Instrument; LVEF = Left Ventricular Ejection Fraction; Tol = Tolerance; VIF = Variance Inflation Factor. ** Significant at the level of $p<0.05$. 


\section{Discussion}

The results of our study suggested that HRQoL of patients with MI improved significantly within the first three months after MI. Predictors of better HRQoL at three months included younger age, STEMI diagnosis, higher LVEF, illness perception, perceived social support, and lower depression symptoms at baseline.

Oginska-Bulik ${ }^{30}$ found that younger patients with MI had higher quality of life. This can be explained by higher physical functioning in younger patients after MI. ${ }^{31}$ Moreover, younger patients are likely to be treated more intensively in consideration of their physical status. ${ }^{32}$ We found that patients diagnosed with STEMI had higher HRQoL at three months post-MI compared to those with NSTEMI. This finding seems also consistent with other research which showed STEMI patients had higher overall HRQoL than those with unstable angina or NSTEMI. ${ }^{33}$ Few studies have compared HRQoL between patients with STEMI and NSTEMI, although disease prognosis is different between these two conditions. Patients diagnosed with STEMI are likely to have relatively low mortality at the early stage; however, NSTEMI patients tend to have a better health condition in the long-term period. ${ }^{33}$ As this study focused on the early stage of recovery from MI, higher HRQoL scores in patients with STEMI are expected. Besides, baseline LVEF was one of significant predictors of HRQoL at three months post-MI. This finding is in line with previous studies, which showed that patients with lower LVEF had poorer HRQoL later. ${ }^{34,35}$ However, a recent study in Korea ${ }^{36}$ found that LVEF was not statistically associated with HRQoL in patients with heart failure. LVEF was regarded as the severity of $\mathrm{MI}^{37}$ as this value has been frequently used for measuring cardiac function in clinical practice. However, the association between LVEF and HRQoL has not been adequately studied in patients with MI. ${ }^{38}$ In addition to the demographic and clinical predictors, three psychosocial factors could be predictive of HRQoL at three months post-MI. Consistent with the results of previous 
studies $^{16,39-41}$, we found that depression symptoms at baseline were predictive of inferior HRQoL at three months. This finding support the results of another Korean study that cardiac patients with depression symptoms reported decreased HRQoL, irrespective of their gender. ${ }^{31}$ Moreover, depression has been consistently identified as an independent predictor, adversely associated with all dimensions of HRQoL—emotional, physical and social—in MI patients in different countries. ${ }^{15,40,41}$

We found that patients' better understanding of their illness at early stages after MI predicted better HRQoL at three months. This finding is in line with the results of a prospective study, which reported higher HRQoL scores at six months in patients with more positive illness perception at early stages post-MI. ${ }^{39}$ Overall, research on the relationship between illness perception and HRQoL post-MI is scant and further research is needed to better understand the role of patient illness perception on recovery from MI.

In the present study, perceived social support was a predictor of HRQoL at the three-month follow-up. This finding supports the results of the Park et al. ${ }^{31}$ study which reported a positive relationship between social support and HRQoL at one month post-MI. We did not investigate if the role of social support on HRQoL after MI differently affected men and women; however, Park et al. reported that social support had stronger impact on HRQoL of Korean women with MI than on men. ${ }^{31}$ A possible explanation of these results may be that Korean people are less likely to visit mental health professionals or clinics, but cope with their problems by depending on their family or friends. ${ }^{42}$ The major features of Korean culture can be referred to as familism ${ }^{43}$ and the communal culture with high solidarity. ${ }^{44}$ Moreover, people in South Korea have negative attitudes towards mental health services. ${ }^{45}$ These cultural features may influence the patient's reliance on close personal relationships for dealing with their mental health, particularly negative emotions, including depression, a major health crisis, interpreting health status and information. Studies focusing on the 
relationship between social support and HRQoL in patients with MI outside South Korea, have reported similar results. Specifically, researchers in Australia found that at six-month follow-up acute MI patients who scored higher in the ESSI showed better HRQoL. ${ }^{32}$ In addition, the influence of perceived social support tended to last up to 12 months after MI when HRQoL. ${ }^{46,47}$ However, perceived overprotection was negatively associated with HRQoL at nine months. ${ }^{48}$

The findings of this study have important implications for health care professionals who are endeavouring to improve patient disease experience and recovery after MI. Comprehensive supportive care is needed to improve the general health status of MI survivors. As found in our model of backward elimination regression analysis, interventions to improve HRQoL in patients post-MI should focus on modifiable predictors including social support, illness perception, and depression management.

Depression is an independent predictor of poor prognosis and mortality after MI. The American Heart Association recommends that all patients with cardiovascular disease should be assessed for depression symptoms and treated if needed. ${ }^{49}$ Korea has the highest suicide rate in the world. ${ }^{50}$ This fact may reflect Korean people generally tend to have negative attitudes toward using professional mental health services and thus use them infrequently. ${ }^{45}$ Thus, patient counselling, education, and treatment of depression should be combined with usual care in the early stage of recovery from MI.

Further, the relationship between illness perceptions and patient outcome has been well documented across different patient groups, including patients with cardiac disease. ${ }^{39}$ Therefore, interventions to alter illness perceptions, especially perceptions of consequences, may be useful in improving HRQoL following an MI.

Perceived social support was another significant predictor of HRQoL in patients with MI at three months. Social support as measured in this study imply the patients' perceived 
emotional support, informational support, and instrumental support they received from others. ${ }^{23}$ Based on questions of the ESSI, helping in household tasks, giving advice and trust would increase patient's perception of the social support. ${ }^{23}$ Therefore, exploring means to support patients emotionally, physically, and financially in early days after MI can be important in helping the patients to improve their HRQoL, overall health and well-being. Yet, perception of overprotection has been shown to have adverse effect on MI patients' sense of well-being. Interventions utilising self-help groups for patients with MI may increase perceived social support and thus HRQoL. ${ }^{31}$ In consideration of the Korean values of familism and communal culture, interventions featuring of group support for patients post MI may be more effective than individual strategies.

The findings of this study should be interpreted with the consideration of several limitations. First, the final model of regression explained only 27.4 per cent of the total variance for HRQoL at three months after MI. This result leads to the fact that HRQoL of MI patients is affected by multiple factors worth investigating by future research. Second, our study used a relatively small sample size, considering the multifactorial nature of HRQoL, future studies should use larger samples to allow for more comprehensive investigation of associated predictors. In addition, we included both patients who suffered a first-time MI and patients with recurrent MI. It is recommended that future studies compare HRQoL between the two groups.

\section{Conclusions}

The results of this study in the Korean population confirm that HRQoL of patients with MI improves over time. At three months post-MI, patients with a higher HRQoL are those who are younger, diagnosed with ST-elevation MI, have higher LVEF, lower level of depression, a better understanding of their illness and higher perceived social support. The findings 
YMHL 1321

indicate that interventions in the form of psychological counselling, patient education, and social support have the capacity to improve patient recovery and HRQoL post-MI. 


\section{References}

1. Foxwell R, Morley C, Frizelle D. Illness perceptions, mood and quality of life: A systematic review of coronary heart disease patients. Journal of Psychosomatic Research. 2013;75:211222.

2. Jernberg $T$, Hasvold $P$, Henriksson $M$, Hjelm $H$, Thuresson $M$, Janzon M. Cardiovascular risk in post-myocardial infarction patients: nationwide real world data demonstrate the importance of a long-term perspective. European heart journal. 2015:ehu505.

3. Kim HM, Kim J, Hwang SY. Health-related quality of life in symptomatic postmyocardial infarction patients with left ventricular dysfunction. Asian nurs. 2015;9:47-52.

4. Lazarewicz MA, Wlodarczyk D, Espnes GA. Quality of Life in Survivors of Myocardial Infarction. In: Alvarenga ME, Byrne D, eds. Handbook of Psychocardiology. Singapore: Springer Singapore; 2016:533-550.

5. Eriksson M, Asplund K, Hochwälder J, Svedlund M. Changes in hope and health-related quality of life in couples following acute myocardial infarction: a quantitative longitudinal study. Scandinavian journal of caring sciences. 2013;27:295-302.

6. Yeng SHS, Gallagher R, Elliott D. Factors influencing health-related quality of life after primary percutaneous coronary intervention for ST-elevation myocardial infarction. Applied Nursing Research. 2016;30:237-244.

7. Kang K, Gholizadeh L, Inglis SC, Han H-R. Correlates of health-related quality of life in patients with myocardial infarction: A literature review. International Journal of Nursing Studies. 2017;73:1-16.

8. Lidell E, Höfer S, Saner H, Perk J, Hildingh C, Oldridge N. Health-related quality of life in European women following myocardial infarction: A cross-sectional study. European Journal of Cardiovascular Nursing: Journal of the Working Group on Cardiovascular Nursing of the European Society of Cardiology. 2015.

9. Pokorney SD, Rodriguez JF, Ortiz JT, Lee DC, Bonow RO, Wu E. Infarct healing is a dynamic process following acute myocardial infarction. Journal of Cardiovascular Magnetic Resonance. 2012;14:62.

10. Heart Foundation. Cardiac rehabilitation summary and resource kit. In: Ministry of Health, ed. Wellington, New Zealand: New Zealand Guidelines Group (NZGG); 2002.

11. Kim HK, Jeong MH, Lee $\mathrm{SH}$, et al. The scientific achievements of the decades in Korean Acute Myocardial Infarction Registry. The Korean Journal of Internal Medicine. 2014;29:703.

12. Fan E, Shahid S, Kondreddi VP, et al. Informed consent in the critically ill: a two-step approach incorporating delirium screening. Critical care medicine. 2008;36:94-99.

13. Pallant J. Multiple regression. In: Pallant J, ed. SPSS survival manual: a step by step guide to data analysis using IBM SPSS. 6th ed. UK: McGraw-Hill Education; 2016:149-168.

14. Ferrans CE, Zerwic JJ, Wilbur JE, Larson JL. Conceptual model of health-related quality of life. Journal of Nursing Scholarship. 2005;37:336-342.

15. Hosseini SH, Ghaemian A, Mehdizadeh E, Ashraf H. Contribution of depression and anxiety to impaired quality of life in survivors of myocardial infarction. International Journal of Psychiatry in Clinical Practice. 2014;18:175-181.

16. Rafael B, Simon A, Drótos G, Balog P. Vital exhaustion and anxiety are related to subjective quality of life in patients with acute myocardial infarct before cardiac rehabilitation. Journal of Clinical Nursing. 2014;23:2864-2873.

17. Arnold SV, Masoudi FA, Rumsfeld JS, Li Y, Jones PG, Spertus JA. Derivation and validation of a risk standardization model for benchmarking hospital performance for health-related quality of life outcomes after acute myocardial infarction. Circulation. 2014;129:313-320.

18. Cha E. Cha Korean translation of the DASS21. Vol 20152014.

19. Henry JD, Crawford JR. The short-form version of the Depression Anxiety Stress Scales (DASS-21): Construct validity and normative data in a large non-clinical sample. British Journal of Clinical Psychology. 2005;44:227-239. 
20. Song $\mathrm{Y}$, Lindquist $\mathrm{R}$. Effects of mindfulness-based stress reduction on depression, anxiety, stress and mindfulness in Korean nursing students. Nurse education today. 2015;35:86-90.

21. Petrie KJ, Cameron LD, Ellis CJ, Buick D, Weinman J. Changing illness perceptions after myocardial infarction: an early intervention randomized controlled trial. Psychosomatic medicine. 2002;64:580-586.

22. Broadbent E, Petrie KJ, Main J, Weinman J. The brief illness perception questionnaire. Journal of psychosomatic research. 2006;60:631-637.

23. Mitchell PH, Powell L, Blumenthal J, et al. A short social support measure for patients recovering from myocardial infarction: the ENRICHD Social Support Inventory. Journal of Cardiopulmonary Rehabilitation and Prevention. 2003;23:398-403.

24. Vaglio J, Conard M, Poston WS, et al. Testing the performance of the ENRICHD Social Support Instrument in cardiac patients. Health and Quality of Life Outcomes. 2004;2:24.

25. Dixon T, Lim LL-Y, Oldridge NB. The MacNew heart disease health-related quality of life instrument: reference data for users. Quality of life Research. 2002;11:173-183.

26. Höfer S, Lim L, Guyatt G, Oldridge N. The MacNew Heart Disease health-related quality of life instrument: a summary. Health Qual Life Outcomes. 2004;2:3.

27. Alphin S, Höfer S, Perk J, Slørdahl S, Zwisler A-DO, Oldridge N. The MacNew heart disease health-related quality of life questionnaire: A scandinavian validation study. Social indicators research. 2015;122:519-537.

28. Fattirolli F, Marchionni N, Höfer S, et al. The Italian MacNew heart disease health-related quality of life questionnaire: a validation study. Internal and Emergency Medicine. 2015;10:359-368.

29. Seneviwickrama K, Samaranayake D, Fonseka P, Galappaththy G, Höfer S, Oldridge N. Psychometric evaluation of the Sinhalese version of MacNew Heart Disease Health Related Quality of Life Questionnaire in patients with stable angina. Health and Quality of Life Outcomes. 2016;14:44.

30. Oginska-Bulik N. Type $D$ personality and quality of life in subjects after myocardial infarction. Kardiologia Polska. 2014;72:624-630.

31. Park SK, Kim H, Cho IS, Ham OK. Gender differences in factors influencing quality of life among patients with coronary artery disease. Journal of Korean Academy of Fundamentals of Nursing. 2009;16:497-505.

32. Hawkes AL, Patrao TA, Ware R, Atherton JJ, Taylor CB, Oldenburg BF. Predictors of physical and mental health-related quality of life outcomes among myocardial infarction patients. BMC Cardiovascular Disorders. 2013;13:69.

33. Kim M-J, Jeon DS, Gwon $\mathrm{H}-\mathrm{C}$, et al. Health-related quality-of-life after percutaneous coronary intervention in patients with UA/NSTEMI and STEMI: The Korean multicenter registry. Journal of Korean medical science. 2013;28:848-854.

34. Coyne KS, Lundergan CF, Boyle D, et al. Relationship of infarct artery patency and left ventricular ejection fraction to health-related quality of life after myocardial infarction: the GUSTO-I Angiographic Study experience. Circulation. 2000;102:1245-1251 1247p.

35. Ecochard R, Colin C, Rabilloud M, et al. Indicators of myocardial dysfunction and quality of life, one year after acute infarction. European Journal of Heart Failure. 2001;3:561-568.

36. Son Y-J, Song Y, Nam S, Shin W-Y, Lee S-J, Jin D-K. Factors associated with health-related quality of life in elderly Korean patients with heart failure. Journal of Cardiovascular Nursing. 2012;27:528-538.

37. Roger VL. Severity of myocardial infarction: New insights on an elusive construct. Circulation. 2009;119:489-491.

38. Pettersen KI, Kvan E, Rollag A, Stavem K, Reikvam A. Health-related quality of life after myocardial infarction is associated with level of left ventricular ejection fraction. $B M C$ Cardiovascular disorders. 2008;8:28. 
39. French DP, Lewin RJP, Watson N, Thompson DR. Do illness perceptions predict attendance at cardiac rehabilitation and quality of life following myocardial infarction? Journal of Psychosomatic Research. 2005;59:315-322.

40. Wang W, Chow A, Thompson DR, Koh K, Kowitlawakul Y, He H-G. Predictors of health-related quality of life among patients with myocardial infarction. Western Journal of Nursing Research. 2014.

41. Wang W, Thompson DR, Ski CF, Liu M. Health-related quality of life and its associated factors in Chinese myocardial infarction patients. European Journal of Preventive Cardiology. 2014;21:321-329.

42. Lee J, Wachholtz A, Choi K-H. A review of the Korean cultural syndrome Hwa-Byung: suggestions for theory and intervention. Asia T'aep'yongyang sangdam yon'gu. 2014;4:49.

43. Kang S-L, Lim S-O. The influence of family values and ethnic national identity to multicultural exclusive attitude - focus on the mediator effect of sensitivity between cultures. Mental Health \& Social Work. 2014;42:91-120.

44. Lee E, Kim J. A semiotic analysis on TV advertising campaigns appealing to Korean sentiments. Archives of Design Research. 2014;27:153-173.

45. Im S, Lee J, Han S. Video-counseling: needs assessment and perception of service utilization. The Korean Journal of Stress Research. 2017;25:57-67.

46. Bucholz EM, Strait KM, Dreyer RP, et al. Effect of low perceived social support on health outcomes in young patients with acute myocardial infarction: results from the VIRGO (Variation in Recovery: Role of Gender on Outcomes of Young AMI Patients) study. Journal of the American Heart Association. 2014;3:e001252.

47. Leifheit-Limson EC, Reid KJ, Kasl SV, et al. Changes in social support within the early recovery period and outcomes after acute myocardial infarction. Journal of Psychosomatic Research. 2012;73:35-41.

48. Joekes K, Maes S, Warrens M. Predicting quality of life and self-management from dyadic support and overprotection after myocardial infarction. British Journal of Health Psychology. 2007;12:473-489.

49. Lichtman JH, Bigger JT, Blumenthal JA, et al. Depression and coronary heart disease recommendations for screening, referral, and treatment: a science advisory from the American Heart Association Prevention Committee of the Council on Cardiovascular Nursing, Council on Clinical Cardiology, Council on Epidemiology and Prevention, and Interdisciplinary Council on Quality of Care and Outcomes Research: endorsed by the American Psychiatric Association. Circulation. 2008;118:1768-1775.

50. OECD. Health at a Glance 2015. Paris: OECD Publishing; 2015. 